\title{
Malpositioned right subcalvian tunnelled catheter and complications of the left pleural cavity
}

\author{
Christos K Stefanou*, Stefanos K Stefanou, Kostas Tepelenis, Thomas Tsiantis, Nikolaos Zikos and Spyridon Koulas \\ Department of General Surgery, General Hospital of Ioannina “G. Hatzikosta”, Makriyianni Avenue, 45001 Ioannina, Greece
}

\begin{abstract}
Introduction: The best way of haemodialysis for patients with Chronic Kidney Disease (CKD), is the arteriovenous fistula, but sometimes the difficulties of this method lead to the percutaneous catheterization of the central vein as a temporary or permanent access.

Case report: The catheterization of the right subclavian vein in a 73 years old patient with end-stage-renal disease was described in this report. The catheter placed in the wrong position, which passed outside of the superior vena cava and entered into the left pleural cavity causing hemo- and pneumothorax.

Discussion: The most preferred vascular access for haemodialysis is the internal jugular vein, due to the fact that it is associated with less complications. Malposition of a Subclavian Catheter Venus (SCV) tunnelled occurs in 1,8\% to 3,7\%. The preferred method is the real time ultrasound guided cannulation.

Conclusion: The position of the catheter should be checked regularly and systematically. Malpositioning should be diagnosed as fast as possible and the right management of complications and removal of the catheter are the first priorities.
\end{abstract}

\section{Introduction}

The number of patients with chronic kidney disease requiring haemodialysis is constantly increasing. There are three ways for haemodialysis vascular access. The best one is the arteriovenous fistula (AVF). Because of the complications and difficulties of this method, the percutaneous catheterization of central vein is used as a temporary or permanent access. The preferred site for catheter insertion is the right internal jugular vein (RIJV). Tunnelled catheters may be placed into the subclavian vein and the femoral vein $(\mathrm{FV})$ if no other options are available.

There are several complications of a central vein catheterization, which can be divided into mechanical, infectious and thrombotic or stenotic group. Cannulation of the subclavian vein because of the anatomy in the area is prone to more complications compared to the other veins, and the most common are considered to be pneumothorax or haemothorax with a frequency of $0-12 \%$ depending on the surgeon's experience [1].

\section{Aim of the study}

In this report, the case of a 73 years old man with end stage renal disease (ESRD) is presented. A haemodialysis catheter insertion was mandatory due to his uremic state. The central venous catheter (CVC) was inserted into the right subclavian vein via indirect (Seldinger) technique. Unexpectedly, the catheter followed a wrong path, was malpositioned and caused severe complications to the patient.

\section{Case report}

A 73-year-old man was presented to our hospital with the need of being inserted a CVC for haemodialysis. The patient had endstage-renal disease (ESRD). His medical history has not revealed any significant problems, except diabetes type 2 and benign hyperplasia of prostate.

The patient was transferred to the operation room. A percutaneous Seldinger technique based on anatomic landmarks and the right subclavian vein approach was chosen for the procedure. Routine standards of care included sterile preparation of the site, sterile draping, Trendelenburg position, caudal traction of the right upper extremity and local anaesthesia. Routine monitoring was also applied for the procedure. Once the subclavian vein was cannulated, a kinkproof guidewire with a flexible J-tip was inserted. A triple-lumen $12 \mathrm{~F}$ diameter was used. The cannulation proceeded smoothly, except for the dilator-insertion, when a small resistance was supposed to be sensed because of the thickness of patient's clavicle. As the J-wire was centrally advanced, the sp02 was decreased shortly (from $97 \%$ to $89 \%$ ), but then immediately reached again within the normal range. Once the catheter was advanced, the three lumens were tested by aspiration of venous blood. Then no aspiration of blood was noticed. The catheter was removed and a new effort of placing the J-wire was attempted. Finally, the catheter was inserted again, assuming to be in the correct position. The three lumens were again checked for resistance to saline flushes and aspiration of blood successfully. The catheter was then stabilized and sutured to the skin at a depth of $15 \mathrm{~cm}$. There was no indication at this time, that the cannulation of CVC may has been malpositioned. The

${ }^{\star}$ Correspondence to: Christos Stefanou, Department of Surgery, General Hospital of Ioannina "G. Hatzikosta", Makriyianni Avenue, 45001 Ioannina, Greece, Tel: +30-6942071910; E-mail: christosstefanou.gr@gmail.com

Key words: central venous catheters, subclavian catheterization, malposition, haemothorax, pneumothorax

Received: April 02, 2019; Accepted: April 09, 2019; Published: April 12, 2019 
patient was hemodynamically stable, his vital signs were normal. An anterior-posterior chest radiography was performed, which revealed that the tip of the catheter was not placed in the right position (superior vena cava), but it was supposed to be placed, in a contralateral subclavian vein. Afterwards a thoracic computed tomography (thorax-CT) scan was performed to obtain a clearer image. The CT scan revealed the presence of the CVC with the right subclavian access which was finally placed in a wrong position outside of the superior vena cava. The tip of the catheter had followed a totally wrong path, perforated the wall of the right subclavian vein, passing behind oesophagus and trachea, closed to the coronary vessels, with his distal point advanced to the posterior mediastinum and finally entering into the left pleural cavity, with direct consequences like pneumomediastinum, and left haemoand -pneumothorax . (Figure 1a-d)

The patient was transmitted to the thoraco-surgery clinic, whereas a left chest tube was placed to drain the hemopneumothorax. The day after the catheter was removed with no bleeding or other complications. The thoracic tube had not been removed until blood and air were fast totally drained, and the thorax was well expanded. The patient remained in the clinic for 10 days. During his hospitalization he remained hemodynamically stable and he did not present any significant problems except for an atrial fibrillation crisis, which was successfully treated with Angoron.

\section{Discussion}

In patients with chronic kidney disease (CKD 5), a good vascular access is an essential component for haemodialysis. Vascular access for HD should provide blood flow of more than $350 \mathrm{ml} / \mathrm{min}$ and the permanent vascular access should be able to be punctured repeatedly. It has been showed that the temporary vascular access was the most common access to initiate HD in CKD 5 and not the AVF fistula, due to late diagnosis $[2,3]$. Moreover, the femoral vein catheterization was the most commonly used first temporary vascular access., because of the low cost and the ease of the technique [4].

Dialysis vascular access related complications may be divided into mechanical, infective and thrombotic or stenotic group. Mechanical complications include arterial puncture, malposition, local hematoma, pneumothorax, haemothorax, chylothorax, air embolism, arrhythmias, accidental removal and failure of the catheterization, vessel perforation, cardiac perforation, cardiac tamponade and death. The most preferred vascular access for HD is the internal jugular vein (IJV), because it is associated with less thrombotic and mechanical complications $[5,6]$. Studies showed that also SCV dialysis access presents low and well comparable to IJV access thrombotic and mechanical complications and SCV access may be recommended as a safe alternative access for haemodialysis patients. Also, free neck mobility after SCV access makes patient more comfortable, as compared to IJV access [7-9].

The right position for the terminal end of a SCV tunnelled catheter is the junction between the superior vena cava (SVC) and the upper part of the right atrium, the cavoatrial junction [10].

Malposition may cause a significant and very serious complication, which occurs in $1.8 \%$ to $3.7 \%$ of central lines insertions [11]. It has been associated with problems of local toxicity, perforation and venous thrombosis. An SVC malpositioned catheter could be found in most cases in the IJV, in the innominate vein, in contralateral innominate vein or in the superior vena cava. It has been reported that the supraclavicular technique for subclavian vein catheterization has a higher success rate and lower incidence of malposition than infraclavicular technique due to wider target area, reliable surface landmarks, and more direct line to the superior vena cava in the right subclavian vein catheterization [12].

The ultrasound guidance is the most recognized method by far, which can provide evidence for the central venous access procedures. Compared with the landmark approach, real-time ultrasound-guided cannulation results in a higher success rate, requires fewer attempts, and has a lower rate of mechanical complications thus, it increases the safety of central venous access via the subclavian route $[13,14]$. The experienced operators still prefer the landmark-guided techniques, although they can cause a considerable number of early mechanical complications and malpositions during central venous catheterization. The risk of mechanical complications, including malposition increased nearly ten times with two attempts and the majority of mechanical complications occurred in procedures involving more than two attempts. In the same study a higher malposition rate was noticed with the left sided central venues access procedures, specifically with the left internal jugular vein $[15,16,17]$.
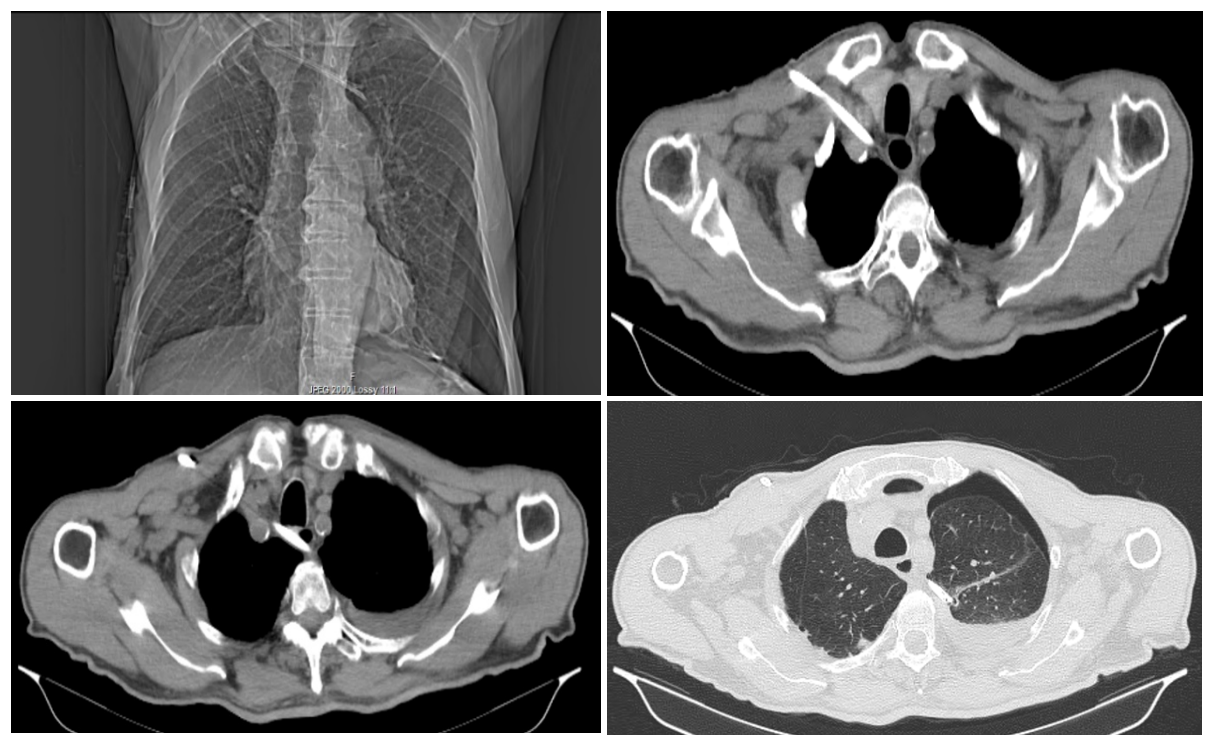

Figure 1. Chest CT 
Various techniques have been suggested to avoid aberrant location of a catheter. The direction of the guidewire J-tip is associated with misplacement of a central venous catheter and higher rate of misplacement is reported when guidewire J-tip is directed cephalad versus caudal [18].

The ultrasound-guided procedure and the absence of technical difficulties cannot guarantee sometimes the right catheter position $[19,20]$. Another study demonstrated that the experience of nontechnical difficulties (harbingers of catheter malpositioning) and even more the availability of an ultrasound-guidance could not raise any suspicion of the catheter malposition, something which needed further radiographic confirmation with a CT scan where a wrong CVC placement was detected $[11,21]$.

Generally, the correct CVC placement can be confirmed by the free blood aspiration, the pressure transduction and the anterior-posterior chest X -ray, which remains the standard method for verifying the course of the catheter segment and the location of the catheter tip [11].

In our case we speculated that the guide wire perforated the vessel wall during initial insertion and followed this wrong course with the above-mentioned consequences. Despite the operator's expertise, there can still be technical difficulties because of the patient's anatomical features and the absence of ultrasound guidance.

\section{Conclusion}

A case of malposition is sometimes underestimated and delayed to be diagnosed. This case highlights that despite the use of safe methods of catheter insertion and confirmation of correct placement through blood aspiration alone, catheter misplacement can still occur and can be difficult to confirm. This can lead to lethal complications and higher mortality rates. Therefore, the catheter position should be regularly and systematically checked prior to their use. When malpositioning is diagnosed, then removal of the catheter is the first priority and then correction of the subsequent complications.

\section{References}

1. Polderman KH, Girbes AJ (2002) Central venous catheter use. Part1: mechanical complications. Intensive Care Med 28: 1-17. [Crossref]

2. Astor BC, Eustace JA, Powe NR, Klag MJ, Sadler JH, et al. (2001) Timing of nephrologist referral and arteriovenous access use: the CHOICE Study. Am J Kidney Dis 38: 494-501. [Crossref]

3. Ravani P, Marcelli D, Malberti F (2002) Vascular access surgery managed by renal physicians: the choice of native arteriovenous fistulas for hemodialysis. Am J Kidney Dis 40: 1264-1276. [Crossref]
4. Chhetri PK, Manandhar DN, Lamichhane S (2009) Vascular access for hemodialysis in Nepal Medical College and Teaching Hospital. Nepal Med Coll J 11: 111-114. [Crossref]

5. Schwab SJ, Beathard G (1999) The hemodialysis catheter conundrum: hate living with them, but can't live without them. Kidney Int 56: 1-17. [Crossref]

6. Quarello F, Forneris G, Borca M, Pozzato M (2006) Do central venous catheters have advantages over arteriovenous fistulas or grafts? J Nephrol 19: 265-279. [Crossref]

7. Vanholder R, Lameire N, Verbanck J, van Rattinghe R, Kunnen M, et al. (1982) Complications of subclavian catheter haemodialysis: a 5-year prospective study in 257 patients. Int J Artif Organs 1982; 5: 297-303. [Crossref]

8. Bourquia A, Jabrane AJ, Ramdani B, Zaid D (1989) [Complications of subclavian vascular approach for haemodialysis]. Ann Med Intrne (Paris) 140: 102-105. [Crossref]

9. Vanherweghem JL, Cabolet P, Dhaene M, Goldman M, Stolear JC, et al. (1986) Complications related to subclavian catheters for haemodialysis. Report and review. Am J Nephrol 6: 339-345. [Crossref]

10. Vascular Access Work Group (2006) Clinical practice guidelines for vascular access Am J Kidney Dis 48: S248-S273. [Crossref]

11. Muhm M, Sunder-Plassmann G, Apsner R, Pernerstorfer T, Rajek A, et al. (1997) Malposition of central venous catheters. Incidence, management and preventive practices. Wien Klin Wochenschr 109: 400-405. [Crossref]

12. Sterner S, Plummer DW, Clinton J, Ruiz E (1986) A comparison of the supraclavicular approach and the infraclavicular approach for subclavian vein catheterization. Ann Emerg Med 15: 421-424. [Crossref]

13. Fragou M, Gravvanis A, Dimitriou V, Papalois A, Kouraklis G, et al. (2011) Real-time ultrasound-guided subclavian vein cannulation versus the landmark method in critical care patients: a prospective randomized study. Crit Care Med 39: 1607-1612. [Crossref]

14. Miller AH, Roth BA, Mills TJ, Woody JR, Longmoor CE, et al. (2002) Ultrasound guidance versus the landmark technique for the placement of central venous catheters in the emergency department. Acad Emerg Med 9: 800-805. [Crossref]

15. Hatfield A, Bodenham A (1999) Portable ultrasound for difficult central venous access. Br J Anaesth 82: 822-826. [Crossref]

16. Muhm M (2002) Ultrasound guided central venous access. BMJ325: 1373-1374. [Crossref]

17. Bodenham AR (2006) Can you justify not using ultrasound guidance for central venous access? Crit Care 10: 175. [Crossref]

18. Park HP, Jeon Y, Hwang JW, Han SH, Bahk JH, et al. (2005) Influence of orientations of guidewire tip on the placement of subclavian venous catheters. Acta Anaesthesiol Scand 49: 1460-1463. [Crossref]

19. Lefrant JY, Cuvillon P, Benezet JF, Dauzat M, Peray P, et al. (1998) Pulsed Doppler ultrasonography guidance for catheterization of the subclavian vein: a randomized study. Anesthesiology 88: 1195-1201. [Crossref]

20. Bold RJ, Winchester DJ, Madary AR, Gregurich MA, Mansfield PF (1998) Prospective, randomized trial of Doppler-assisted subclavian vein catheterization. Arch Surg 133: 1089-1093. [Crossref]

21. Moskal TL, Ray CE Jr (1999) Left mediastinal central line malposition--a case report. Angiology 50: 349-353. [Crossref]

Copyright: (C2019 Stefanou C. This is an open-access article distributed under the terms of the Creative Commons Attribution License, which permits unrestricted use, distribution, and reproduction in any medium, provided the original author and source are credited. 